\title{
Towards Micropolitical Foundations of Public Finance*
}

\author{
Torsten Persson Gérard Roland Guido Tabellini
}

September 10, 1997

\begin{abstract}
Observed fiscal policy reflects the incentives embedded in political institutions. In this paper, we illustrate the effects of two general institutional features: separation of powers, which is common in Presidential-Congressional political systems, and legislative cohesion, which is typical of parliamentary systems. Compared to a simple legislative game, separation of powers brings about a smaller size of government and lower waste, whereas legislative cohesion induces a more equal distribution, but more waste and higher taxes.

Keywords: political economics, comparative politics, rents, incentives.

JEL classification: $\mathrm{H} 1, \mathrm{~A} 1$

How can opportunistic policymakers be induced to behave in the voters interest? Which features of political institutions are most helpful in this regard? How do political institutions resolve or mitigate the conflict of interest among different groups of citizens? These fundamental questions are typically ignored by the two prevalent and opposite traditions in public finance. Traditional neoclassical theory is entirely normative and assumes a benevolent planner with a well-defined social welfare function. This has been criticized as a caricature by the public choice school, which argues that politicians rationally follow their self-interest. Positive public choice theory, however, typically relies on an alternative caricature: the

*The authors are from: IIES, Stockholm University; ECARE, Université Libre de Bruxelles; and IGIER, Bocconi University, respectively. They thank the European Commission for financial support (a TMR grant) and Christina Lönnblad for editorial assistance.
\end{abstract}


malevolent Leviathan policymaker that replaces the benevolent Pigovian planner is solely maximizing her own rents. The voters' interest and the possible conflicts among them are generally disregarded, and political institutions do not play any part in the analysis. To put it more bluntly: both traditions lack micro-political foundations. Building a bridge between these two traditions - combining their main insights - is an important task for public finance. This requires addressing the above questions regarding how well democratic institutions align the interests of voters and the incentives of self-interested politicians. This paper summarizes a recent line of research attempting to provide such micro-political foundations.

Section 2 lays out the basic model, simplifying the richer framework of Persson, Roland and Tabellini (1997b). Tax and redistributive policies are chosen in a simple legislative bargaining game in the style of Baron and Ferejohn (1989). Each legislator represents the voters in an electoral district. There is a redistributive conflict between voters in different districts, but there is also an agency problem as the politicians have the power to divert resources for their own benefit. We embed the legislative bargaining in an electoral framework similar to those of Ferejohn (1986) and Persson, Roland and Tabellini (1997a). Even though voters can discipline their representatives by not re-electing them if they divert too much, the representatives succeed in maximizing tax revenues and keep some remaining rents in equilibrium. This is a first political distortion. A second distortion is that equilibrium redistribution is directed towards a minority.

The remainder of the paper then investigates how these distortions are altered by different features of richer political institutions. In Section 3, we consider an essential feature of real-world presidential-congressional systems, namely separation of powers. Unlike in the simple legislature, proposals regarding the level of taxes and the allocation of tax revenue are made by different legislators (congressional committees), which are held accountable by voters in different districts. As in Persson, Roland and Tabellini (1997a), this separation of powers diminishes the first political distortion: equilibrium taxes and rents to politicians are unambiguously lower. But the second distortion remains.

Section 4 studies a feature more closely associated with parliamentary systems, namely legislative cohesion. As shown in Diermeier and Feddersen (1996), a break up of the government entails a costly loss of agenda setting powers. This strengthens the governing coalition's incentive to vote together on proposed legislation and dampens the second political distortion: the benefits of redistribution are now enjoyed by a majority of the voters. But taxes and rents to politicians are now back at as high a level as in the simple legislature. 


\section{A simple legislative game}

Consider a simple legislature with three representatives. Each of them represents a constituency with homogeneous voters, the size of which is normalized to unity. Each voter in district $i$ wants to maximize

$$
u^{i}=U\left[(1-\tau)+r^{i}\right] .
$$

Voter income is normalized to $1, \tau$ is a tax rate common to all districts, and $r^{i}$ is a redistributive transfer payment to district $i$. The government budget fulfills

$$
3 \tau=r+s,
$$

where $r=\sum_{i} r^{i}$ and $s=\sum_{i} s^{i}$ respectively represent aggregate transfers and aggregate resources diverted in the political process to the benefit of politicians. Thus, item $s^{i}$ benefits the representative from region $i$ but nobody else. From the viewpoint of voters, $s>0$ thus represents a waste of resources. All items appearing in the government budget constraint are constrained to be non-negative. Politicians seek to maximize:

$$
v^{i}=s^{i}+w D^{i},
$$

where $D^{i} \in\{0,1\}$ is a dummy variable taking the value $D^{i}=1$ if the politician is reelected at the end of the period and 0 otherwise, and $w>0$ constitutes the exogenous private benefit of holding office in the future. We assume that voters in region $i$ coordinate on a utility-maximizing re-election rule where $D^{i}=1$ if and only if $u^{i} \geq b^{i}$ where $b^{i}$ is a level of "reservation utility". If $D^{i}=0$, voters instead appoint an opponent randomly selected from a set of candidates identical to the incumbent in all respects. ${ }^{1}$

The model incorporates conflicts of interest in three dimensions. Voters disagree across districts over the distribution of $r$, for given $\tau$ and $s$; politicians disagree over the distribution of $s$, for given $\tau$ and $r$; finally, voters and politicians disagree over how $\tau$ are to be distributed between $s$ and $r$. How these conflicts of interest are resolved depends on the political institutions in place, specifically on the assumed form of legislative bargaining. Note also that politicians have

\footnotetext{
${ }^{1}$ This framework is a static simplification of a full-fledged intertemporal model. Persson, Roland and Tabellini (1997a, 1997b) solve endogenously for the benefits of office (the term $w$ ), as the expected present value of future rents $s$. The discussion in Persson (1997) also suggests that the results may be robust to the assumptions about voter behavior and legislator motives.
} 
the power to appropriate resources; but as they value holding office in the future, they can be disciplined through elections. How well this mechanism works also depends on the political institutions.

We first analyze a simple legislature without separation of powers or legislative cohesion. The timing is as follows: (1) Nature randomly chooses an agenda-setter $a$ among the three legislators. (2) Voters set their reservation utilities, conditional on whether their representative is the agenda setter or not, and these strategies are observed by everybody. (3) The agenda setter proposes a policy $\left(\tau,\left\{r^{i}\right\},\left\{s^{i}\right\}\right)$. (4) The legislature votes. If at least another legislator supports the proposal, it is implemented. If not, a default outcome is implemented with $\tau=\sigma+\rho<1$, $s^{i}=\sigma>0$, and $r^{i}=\rho>0$. (5) Voters observe $\tau$ and $\left\{r^{i}\right\}$, and elections are held.

There is a unique sequentially rational equilibrium. It has four fundamental features (see Persson, Roland and Tabellini (1997b) for a more complete derivation). First, there is a minimum winning coalition of two legislators. Satisfying a coalition partner is costly for the agenda setter: the resources offered to a coalition partner can neither be spent on rents for $a$ nor on transfers to $a$ 's constituency. Hence, in equilibrium one legislator, $n$ say, is left out of the winning coalition and gets $s^{n}=r^{n}=0$.

Second, voters in regions $i \neq a$ are involved in a Bertrand competition, where they bid down their reservation utilities. Since the minority does not receive any transfers, voters in both districts $i \neq a$ compete for being included in the winning coalition. The agenda-setting legislator always chooses the representative whose votes are "cheaper" to buy as a coalition partner. Thus, the voters of the district included in the majority, $m$ say, cannot afford to be more demanding than voters in district $n$. Because of this discontinuity in voters' payoffs inside and outside the majority, the only equilibrium has both regions asking for $r^{i}=0$, and setting their reservation utility to $b^{i}=U\left(1-\tau^{L}\right)$, where $\tau^{L}$ is the equilibrium tax rate.

Third, legislators in the winning coalition appropriate some rents. Consider the joint welfare of legislators $a$ and $m$. They always have the option of not seeking reappointment. In this case, it is jointly optimal to pursue a "Leviathan" policy maximizing tax revenue and appropriating all resources, thereby achieving a joint payoff of 3 in the current period. The alternative is to please the voters and appropriate a smaller overall amount of rents, $s$, thereby achieving joint welfare of $(s+2 w)$. In equilibrium, the voters must leave the legislators indifferent between these two options. Hence, the overall rents appropriated in equilibrium amount to $s^{L}=3-2 w$. How are these rents split among legislators? The agenda setter is the residual claimant. She nails legislator $m$ to her status quo payoff, leaving 
her $s^{m}=\sigma-w$, and gets the remainder for himself: $s^{a}=3-\sigma-w$. Note that legislators are disciplined by voters in district $a$; the other voters are engaged in Bertrand competition, and cannot exert any discipline anyway.

Fourth, tax revenues are maximized. This is in the interest of the voters in the agenda setter district, who are the only ones who might influence policy choices through their reservation utilities. Specifically, voters in the agenda-setting region determine their reservation utility $b^{a}$ so as to maximize $U\left(1-\tau+r^{a}\right)$, subject to the budget constraint $3 \tau=r^{a}+s$ and the incentive constraint $s \geq 3-2 w$. Combining the two constraints, we have $r^{a} \leq 2 w-3(1-\tau)$. Clearly, the optimum is to have $\tau=1$ and $r^{a}=2 w$, which is implemented by voters in district $a$ setting their reservation utility at $b^{a}=U(2 w)$.

We can summarize the preceding discussion as follows:

Proposition 1. In the simple legislature we have $\tau^{L}=1, s^{L}=3-$ $2 w, r^{L}=r^{a L}=2 w$ with $r^{i L}=0$, for $i \neq a$. This equilibrium is supported by reservation utilities $b^{a}=U(2 w)$ and $b^{i}=U(0)$ for $i \neq a$.

A social optimum - given any social welfare function that is symmetric across districts, but does not include the utility of politicians - would set $s=0$ and $r^{i}=\tau$ for all $i .^{2}$ Compared to this benchmark, there are thus two "political distortions" in the equilibrium of this section. First, redistribution, and accordingly private consumption, is severely biased towards the district of the agenda-setter. Second, the equilibrium cannot circumvent the agency problem of legislators diverting tax revenues for their own benefit. As we shall see, more realistic political institutions dampen at least one of these distortions.

\section{Separation of powers}

As the Founding Fathers of the American constitution had clearly understood, "checks and balances" on government activities may help the voters to discipline elected officials. The underlying problem is that a political constitution is like an incomplete contract: this is what allows politicians to reap rents from office. This problem can be alleviated by separation of powers. ${ }^{3}$ In fact, few real world

\footnotetext{
${ }^{2}$ In this set-up, $\tau$ is indeterminate but would be set to 0 if taxes were distortionary.

${ }^{3}$ As in the contract literature, asymmetric information is another source of rents. Persson, Roland and Tabellini (1997a) demonstrate that separation of powers is helpful in curtailing this source of rents, as well.
} 
political institutions allow such massive concentrations of proposal power as the simple legislature we have just studied.

Separation of powers obtains most clearly in presidential systems, where the executive is directly elected. In presidential-congressional systems like the US, congressional committees have considerable agenda-setting powers, but only over specific policy dimensions. Thus, the agenda setting power is split among different legislators. That is also our assumption in this section: we consider a two-stage budget procedure, where taxes and the allocation of expenditures are proposed by two different legislators.

Consider the following modified timing. (1) Nature randomly chooses two different agenda-setters $a_{\tau}$ and $a_{g}$, the "finance committee" and the "expenditure committee", among the three legislators. (2) Voters set their reservation utilities, conditional on the status of their legislator. (3) $a_{\tau}$ proposes a tax rate $\tau$. (4) Congress votes. If approved by a majority, the proposal becomes law if not, a default tax rate $\tau=\sigma+\rho$ is set where $\sigma+\rho>1-w$. (5) $a_{g}$ proposes $\left\{r^{i}\right\}$ and $\left\{s^{i}\right\}$ subject to $3 \tau \geq r+s$. (6) Congress votes. If rejected by a majority, the default allocation is $r^{i}=\rho$ and $s^{i}=\tau-\rho$. (7) Elections are held.

There are two relevant differences between this model and the one in the previous section. First, as already discussed, there now are two agenda setters rather than one. Second, policy decisions are made sequentially, first on the overall size of government and then on the allocation of spending. Note that not only proposals are sequential, but so are Congressional votes. Specifically, spending proposals in the second stage are constrained by the outcome of Congressional votes over the size of tax revenues. As explained in Persson, Roland and Tabellini (1997a), a two-stage procedure is essential to exploit the benefits of separation of power in this context.

How does the equilibrium differ from that in the previous section? Once more, there is a minimum winning coalition and Bertrand competition, so that voters in region $i \neq a_{g}$ demand $r^{i}=0$ and set $b^{i}=U\left(1-\tau^{S}\right)$. But there are two other diverging features in the equilibrium.

First, consider waste. In the previous section, legislators going for the short run option of appropriating all resources could set $\tau=1$. Here they are instead constrained by the tax rate approved at stage (4). Therefore, the incentive constraint on the minimum allowable rents at stage (5) of the game is: $s \geq 3 \tau-2 w$. If $\tau<1$, this implies smaller equilibrium rents than in the simple legislature. The allocation of rents among legislators follows the same logic; it can be shown that: $s^{m}=\tau-w-\rho ; s^{n}=0$. 
Next, consider the decision over taxes and, in particular, proposal by the taxation committee $a_{\tau}$. As voters in district $a_{\tau}$ do not receive any transfers, they would like $\tau$ to be as low as possible. This is contrary to the interests of legislator $a_{\tau}$, however, for whom higher taxes imply larger rents in expected value. The reason is that the two legislators $i \neq a_{g}$ not on the expenditure committee are in the majority at stage (6) with $50 \%$ probability each. All legislators are thus residual claimants on higher taxes in expected terms. Hence, there is a lower bound on the tax rate that $a_{\tau}$ is willing to propose and $i \neq a_{g}$ is willing to approve. It can be shown that this incentive constraint can be written as: $\tau \geq 1-w \cdot{ }^{4} \mathrm{~A}$ tax rate lower than $1-w$ would not be politically feasible, because no legislator at stages (3) and (4) would be willing to propose it or to approve it, even at the cost of losing the election. Voters in district $a_{\tau}$ thus insist on the minimal tax rate, $\tau=1-w$, and reservation utilities for $i \neq a_{g}$ are: $b^{i}=U(w)$. Voters in district $a_{g}$ in turn insist on maximal incentive-compatible transfers, given the equilibrium tax rate. They thus set $b^{a_{g}}=U\left(1-\tau^{S}+r^{a_{g}}\right)=U(3 w)$. We thus have:

Proposition 2. Under separation of powers, we get $\tau^{S}=1-w, s^{S}=$ $3-5 w, r^{S}=2 w$ and $r^{i}=0$ for $i \neq a_{g}$. The equilibrium is supported by reservation utilities $b^{a_{g}}=U(3 w)$ and $b^{i}=U(w)$ for $i \neq a_{g}$.

Compared to the simple legislature, a presidential-congressional system with separation of powers thus achieves lower waste via a lower equilibrium tax rate. The two-stage budget process with different agenda setters creates checks and balances that can be exploited by the voters. But the other political failure - an asymmetric distribution, favoring a minority of voters - remains.

\section{Legislative Cohesion}

A central feature of the Presidential-congressional political system described above is the fluidity of legislative coalitions: different coalitions are formed over different issues or at different points in time. This is at the core of the Bertrand competition result, where the agenda setter pits one group of voters against another; it is also

\footnotetext{
${ }^{4}$ Specifically, the incentive constraint on $a_{\tau}$ is $\frac{1}{2} s^{m}+w=\frac{1}{2}(\tau-\rho-w)+w \geq \frac{1}{2}(1-\rho)$, or simplifying, $\tau \geq 1-w$. Voters in districts $i \neq a_{g}$ prefer tax rate $1-w$ to the default rate, given that $1-w<\sigma+\rho$. Finally, legislators from districts $i \neq a_{g}$ have no incentive to reject the proposed tax rate $1-w$. This would lead to their being ousted, in which case their expected payoff is only $\frac{1}{2} \sigma$, which is less than $\frac{1}{2} s^{m}+w=\frac{1}{2}(1-\rho)$, as $\sigma+\rho<1$. See Persson, Roland and Tabellini (1997b) for a more extensive discussion.
} 
central to the separation of powers, in that legislators are not sure to benefit from high taxes because they are not certain whether they will be included in the winning majority at later stages. In parliamentary systems, on the other hand, the same legislative coalition tends to stick together over time and across policy issues. We now formulate a model exhibiting this property. Also in this setting, two different legislators make proposals on taxes and expenditures, respectively. No vote is taken, however, until both proposals have been made. It is therefore appropriate to identify these legislators with cabinet ministers and the proposal phase with the budget preparation inside the government. Two key assumptions induce legislative cohesion: both coalition partners can veto any proposal, and their expected payoff after a "government crisis" is reduced.

The new timing is: (1) Nature chooses a prime minister, who also acts as expenditure minister: $a=a_{g}$. (2) The prime minister forms a government by appointing a partner to be finance minister: $m=a_{\tau} \cdot{ }^{5}(3)$ Voters set their reservation utilities. (4) The finance minister proposes a tax rate. (5) The prime minister proposes expenditures $\left\{r^{i}\right\},\left\{s^{i}\right\}$ subject to the budget constraint that they are compatible with the proposed tax rate. (6) Both members of government can veto the proposal. If neither of them does, the proposal passes. If at least one of them vetoes, the government breaks down and a default policy is implemented with $\tau^{\prime}=\tau^{L}, r=r^{L}, r^{i \prime}=r^{\prime} / 3, s^{\prime}=s^{L}, s^{i \prime}=s^{\prime} / 3$, where the $L$ superscript denotes the equilibrium of the simple legislature. (7) Elections are held.

The default policy may appear strange at first sight. Its payoff matches the expected payoffs of the simple legislature. It is a shortcut for a more complex game, where a government crisis leads to a subgame where decisions are made as in the simple legislature (see Persson, Roland and Tabellini (1997b)). ${ }^{6}$ This captures the feature mentioned above: the two government partners recognize that they have valuable agenda-setting powers inside the government and that a breakup is costly. As a result, the agenda setting power is diluted and both government partners have some bargaining power against each other.

In this regime, equilibrium waste is back to the same level as in the simple legislature. The maximum threat that the government can impose on the voters, if the two coalition partners expect not to be re-elected, is to set $\tau=1$ and $r=0$, as in section 2 . Thus they jointly have to receive $s \geq 3-2 w$. These rents are then

\footnotetext{
${ }^{5}$ If the prime minister distributed the portfolios endogenously, she would indeed make this choice: the expenditure ministry is most valuable, as it controls the distribution of rents $\left\{s^{i}\right\}$.

${ }^{6}$ A richer model along the lines of Diermeier and Feddersen (1996) or Baron (1987) would have a new process of government formation following a crisis.
} 
split among legislators according to their bargaining power, which here reflects their veto rights. In particular, the finance minister will veto any proposal $s^{m}$ that does not give her at least as much as after a government crisis, which after some algebra yields: $s^{m}=1-\frac{5}{3} w$. Together with the budget constraint this implies $r \leq 2 w-3(1-\tau)$, the same incentive constraint as in the simple legislature.

Bilateral monopoly replaces competition in the redistribution game between voters, however. Equilibrium claims on aggregate $r$ by voters in districts $a$ and $m$ have to be mutually consistent. But that $r$ can be split in many ways. ${ }^{7}$ We can parametrize the possible allocations by $\alpha$ and set $r^{m}=\alpha r$ and $r^{a}=(1-\alpha) r$. It is easy to see that the utility of voters in both districts is increasing in $\tau$ (and thereby in $r$ ) as long as $\frac{1}{3} \leq \alpha \leq \frac{2}{3}$. Hence, under this condition, voters in both districts benefit from high taxes, given the incentive constraint, and will therefore insist on maximal taxation. This is done by setting their reservation utilities at $b^{m}=U(\alpha 2 w)$ and $b^{a}=U((1-\alpha) 2 w)$.

The above argument can be summarized as:

Proposition 3. Under legislative cohesion, there are multiple equilibria with $\tau^{C}=1, s^{C}=3-2 w, r^{C}=2 w$ and $r^{a}=(1-\alpha) r, r^{m}=\alpha r$. The equilibria are supported by reservation utilities: $b^{a}=U((1-\alpha) 2 w)$, $b^{m}=U(\alpha 2 w)$ and $b^{n}=U(0)$.

Taxation and waste are back at the same levels as in the simple legislature. On the other hand, redistribution now benefits a majority of the voters. Legislative cohesion thus brings about a more equal distribution of income. In this setting, one can show that this is not enough to compensate voters for the higher waste; their ex ante expected utility is always higher under separation of powers than under legislative cohesion. This is not general, however. As demonstrated by Persson, Roland and Tabellini (1997b), the more equal sharing in a parliamentary system is also associated with a higher provision of (Samuelsonian) public goods, which may compensate for the higher rents (in an expected utility sense).

\section{A Research Agenda}

The variety of observed and hypothetical political constitutions suggests several topics for future theoretical and empirical research. How do different procedural

\footnotetext{
${ }^{7}$ The setting is equivalent to a delegation game with observable contracts, as in Fershtman, Judd and Kalai (1991).
} 
rules for breaking of governments and dissolving of legislatures, such as those studied by Baron (1997), affect the bargaining powers within governments and the policy outcome? How does the recent, and much debated, US reform of presidential line item veto affect the voters' ability to exploit the separation of powers between the president and the congress in their own favor? Do stark predictions about the level and composition of government spending under presidential and parliamentary systems, such as those in Persson, Roland, and Tabellini (1997b), hold when confronted with data on political institutions and fiscal outcomes across countries and time? The examples in this paper and the work on which they draw suggest that this research agenda is entirely operational.

\section{References}

[1] Baron, D. (1997), "Comparative dynamics of parliamentary government", mimeo, Stanford University.

[2] Baron, D., and J. Ferejohn (1989), "Bargaining in legislatures", American Political Science Review 83, 1181-1206.

[3] Diermeier, D., and T. Feddersen (1996), "Disciplined coalitions and redistribution: The effect of the vote of confidence procedure on legislative bargaining", mimeo, Northwestern University.

[4] Ferejohn, J. (1986), "Incumbent performance and electoral control", Public Choice 50, 5-26.

[5] Fershtmann, C., K. Judd and E. Kalai (1991), "Observable contracts: Strategic delegation and cooperation", International Economic Review 32, 551-559.

[6] Persson, T. (1997), "Economic policy and special interest politics", forthcoming in Economic Journal.

[7] Persson, T., G. Roland, and G. Tabellini (1997a), "Separation of powers and political accountability", forthcoming in Quarterly Journal of Economics.

[8] Persson, T., G. Roland, and G. Tabellini (1997b), "Comparative politics and public finance", mimeo, Harvard University. 